\title{
Editor's Note: Special Issue on the Life and Work of Donald Capps (1939-2015)
}

\author{
Curtis W. Hart ${ }^{1}$
}

Published online: 2 February 2018

(c) Springer Science+Business Media, LLC, part of Springer Nature 2018

When Nathan Carlin and I began first discussing putting together a Special Section devoted the work and legacy of his mentor and friend Donald Capps I had no idea of how long this might take nor did I much care. I was pleased that Robert Dykstra, also a friend and colleague of Donald Capps, would join him in this enterprise of recruitment and organization of the articles that comprise the Special Section of the Journal that follows. The breadth and content of these contributions speak to the reach of Donald Capps' across cultures and disciplines. I am certain that the impact of this collection will be felt for some time to come.

I have already spoken of my relation with Don Capps in the memorial piece I wrote about him that was first published online in the Journal in September 2015 only a few weeks after his tragic death in his hometown of Princeton, New Jersey. I stated in that article that he and I had only met briefly twice at academic conferences years before though that relationship deepened considerably after I took on the editorship of this Journal where he had been a contributor and an Editorial Board member for some years. My predecessor, Donald Ferrell, informed me that Don's evaluation of articles and his professional friendship in the art (and I use this word advisedly) of editing would be of value in the years ahead. How right Donald Ferrell was. I received from Don Capps on several occasion the careful and critical judgments befitting the sage advice of any consigliore for a comparative neophyte in this position. For this I will always be grateful.

As I write this today, I think back on how unworried I was about the time it might take to forge together the contributions for this Special Section. I do not know the precise length of time it took to put it together. But I do believe that our willingness to trust one another and to move forward with our "eyes on the prize" of a first rate product suggests something of Donald Capps' spirit. Any person who could write so knowingly and empathically

Curtis W. Hart

cuh9001@med.cornell.edu

1 New York, USA 
about the traps and pitfalls of "the depleted self" would understand how important it is in any creative venture (and scholarship with several voices as found in this Special Section is surely one of these) to take the time it takes and to keep at it. Time may be a commodity in business or academia but it also has an eternal and transcendent character. Donald Capps knew both. He could not have published all those books and met all those deadlines without a respect for fulfilling one's professional and contractual obligations. But he also possessed a sense of the need to take time and make room for revelation to enter into consciousness and illuminate the creative process as it dawns and then struggles to be born and expressed. In that way, among others, Donald Capps is fully present in the pages that follow.

A final note: we are pleased to report that Springer Publishing asked for and received from us the names of our four most prolific and dependable peer reviewers for 2017 to be posted on their website along with peer reviewers from other of Springer's many publications. These persons who are the representatives for the Journal of Religion and Health are Lindsay Carey, Donald Owens, Harold Koenig, and Ralph Hood. We salute and heartily thank them all. 